\title{
Night-Time Oxidation of a Monolayer Model for the Air-Water Interface of Marine Aerosols-A Study by Simultaneous Neutron Reflectometry and in Situ Infra-Red Reflection Absorption Spectroscopy (IRRAS)
}

\author{
Ben Woden ${ }^{1}\left(\mathbb{D}\right.$, Maximilian W. A. Skoda ${ }^{2}\left(\mathbb{D}\right.$, Matthew Hagreen ${ }^{1}$ and Christian Pfrang ${ }^{3, *(D)}$ \\ 1 Department of Chemistry, University of Reading, Reading, Whiteknights RG6 6AD, UK; \\ rt011604@pgr.reading.ac.uk (B.W.); matthew_hagreen@hotmail.co.uk (M.H.) \\ 2 ISIS Pulsed Neutron and Muon Source, Science and Technology Facilities Council (STFC), Rutherford \\ Appleton Laboratory, Didcot, Oxfordshire OX11 OQX, UK; maximilian.skoda@stfc.ac.uk \\ 3 School of Geography, Earth and Environmental Sciences, University of Birmingham, Birmingham, \\ Edgbaston B15 2TT, UK \\ * Correspondence: c.pfrang@bham.ac.uk; Tel.: +44(0)-121-4145-519
}

Received: 12 September 2018; Accepted: 24 November 2018; Published: 30 November 2018

\begin{abstract}
This paper describes experiments on the ageing of a monolayer model for the air-water interface of marine aerosols composed of a typical glycolipid, galactocerebroside (GCB). Lipopolysaccharides have been observed in marine aerosols, and GCB is used as a proxy for these more complex lipopolysaccharides. GCB monolayers are investigated as pure films, as mixed films with palmitic acid, which is abundant in marine aerosols and forms a stable attractively mixed film with GCB, particularly with divalent salts present in the subphase, and as mixed films with palmitoleic acid, an unsaturated analogue of palmitic acid. Such mixed films are more realistic models of atmospheric aerosols than simpler single-component systems. Neutron reflectometry (NR) has been combined in situ with Fourier transform infra-red reflection absorption spectroscopy (IRRAS) in a pioneering analysis and reaction setup designed by us specifically to study mixed organic monolayers at the air-water interface. The two techniques in combination allow for more sophisticated observation of multi-component monolayers than has previously been possible. The structure at the air-water interface was also investigated by complementary Brewster angle microscopy (BAM). This study looks specifically at the oxidation of the organic films by nitrate radicals $\left(\mathrm{NO}_{3} \bullet\right)$, the key atmospheric oxidant present at night. We conclude that $\mathrm{NO}_{3} \bullet$ oxidation cannot fully remove a cerebroside monolayer from the surface on atmospherically relevant timescales, leaving its saturated tail at the interface. This is true for pure and salt water subphases, as well as for single- and two-component films. The behaviour of the unsaturated tail section of the molecule is more variable and is affected by interactions with co-deposited species. Most surprisingly, we found that the presence of $\mathrm{CaCl}_{2}$ in the subphase extends the lifetime of the unsaturated tail substantially-a new explanation for longer residence times of materials in the atmosphere compared to lifetimes based on laboratory studies of simplified model systems. It is thus likely that aerosols produced from the sea-surface microlayer at night will remain covered in surfactant molecules on atmospherically relevant timescales with impact on the droplet's surface tension and on the transport of chemical species across the air-water interface.
\end{abstract}

Keywords: aerosol; monolayer; nitrate radical; cerebroside; palmitic acid; palmitoleic acid; neutron; reflectivity; infra-red; Brewster angle microscopy 


\section{Introduction}

In papers published in 1983 [1] and 1999 [2], it was noted that organic films formed on the surface of atmospheric aerosol particles and that the reactivity both of the aerosol particles underneath and of the species that make up the organic films themselves were different from what would be expected if each were encountered individually in the atmosphere. Donaldson and Vaida published a seminal review in 2006 [3] which brought together the subset of the body of scientific knowledge regarding the behaviour of molecular monolayer organic films at the air-water interface relevant to atmospheric processes.

The role of atmospheric aerosols in cloud formation is a topic of key importance for climate science. The relationship between aerosol concentrations and the radiative forcing attributable to clouds is exceptionally complex, poorly understood, and difficult to measure [4]. The study of these organic films at the air-water interface may form a key part of solving this puzzle. Many organic compounds will oxidise in the atmosphere to form secondary organic aerosol (SOA). Changes in these reactions due to the partitioning of the relevant reactants to the surface of water droplets in the atmosphere will, therefore, affect the manner in which SOA is formed and distributed. The films' effects on the physical nature of the water droplets onto which they partition is also of vital importance, as the surface tension of the droplets is lowered by the presence of these films [3], meaning that the removal of such films by oxidation can cause an increase in surface tension. The surface tension of water droplets plays a key role in regulating the growth of clouds [5]. The water droplets on which these organic films form are thus atmospherically important and are modified by virtue of their interaction with each other in a monolayer at the air-water interface. The film coating can also act as a barrier to water uptake by and evaporation of the droplet and can inhibit the transport of various atmospheric species from the gas to the aqueous phase [6-13]. Conversely, the film can act as a "2D solvent" for atmospheric species that would not normally partition to the aqueous phase, or can alter the solvation behaviour of those that would [14-18]. Very recently, Forestieri et al. [19] studied the surface tension effects on sea spray aerosol mimics (oleic, palmitic, myristic acids, and their mixtures) using a surface film model to establish the properties that surface-active organic molecules must have to substantially impact on the aerosol's activation efficiency. They found that the properties of surface-active marine-derived organic molecules must differ substantially from the simple fatty acids they studied e.g., by having larger molecular areas.

While the discussion here is focused on the presence of thin organic films on particles, it should be noted that particles have been shown to be phase separated and may contain 3D organic surface layers or even more complex 3D self-assembled structures, leading to particle morphologies that may differ substantially from the construct of a monolayer or sub-monolayer film on an electrolyte subphase [20-22].

The present study investigates the oxidation of model marine aerosol systems via reaction with nitrate radicals $\left(\mathrm{NO}_{3} \bullet\right)$, the key atmospheric oxidant present at night $[23,24]$. This oxidant takes over in the absence of sunlight from the dominant day-time initiator of atmospheric oxidation, $\mathrm{OH} \bullet$, together with the less reactive ozone $\left(\mathrm{O}_{3}\right)$ that is present throughout the day and night (e.g., $[25,26]) . \mathrm{NO}_{3} \bullet$ primarily reacts with organic species by attacking carbon-carbon double bonds (e.g., $[23,27-29]$ ) and oxidising the new terminal groups to produce a variety of carboxylic acid and aldehyde fragments [23]. These reactions may be important in the production of atmospheric SOA, so changes to their nature and kinetics could be important in their own right, however their key relevance comes in that they determine the lifetime and ageing of the monolayer and, thus, the extent to which the water droplet is affected by all the physical and chemical changes detailed above that are due to the presence of that monolayer. Most monolayer studies to date (e.g., [30-33]) have focused on the less reactive initiator of the atmospheric oxidation ozone $\left(\mathrm{O}_{3}\right)$ that is known to be unreactive towards saturated surfactants (e.g., [34]). However, saturated surfactants have recently been shown to be of particular atmospheric importance [35], therefore processes that can attack saturated organic compounds are of particular interest. Understanding the night-time atmospheric ageing by $\mathrm{NO}_{3} \bullet$, in addition to the chemistry of the dominant day-time oxidant $\mathrm{OH} \bullet$ (e.g., [36]) and photochemical 
reactions that have recently received lots of attention (e.g., [37]) is therefore an important focus of current research. It is thus essential to investigate the $\mathrm{NO}_{3} \bullet$ chemistry at the air-water interface given the scarcity of previous studies [38,39].

Marine aerosols are highly variable in composition. Saturated fatty acids have been detected in abundance, particularly palmitic acid (PA) [40]. PA is commonly used as a proxy for marine aerosols [41]. Lipopolysaccharides have been discovered both in the sea surface microlayer [42] and in atmospheric aerosol [43]. Facchini et al. [43] found that sea water microgels, mainly composed of lipopolysaccharides, are preferentially transferred to the submicron aerosol size fraction during bubble bursting. Cerebrosides provide a good proxy species for the more complex lipopolysaccharides at the air-water interface [41], therefore the present study focuses on the oxidation of the glycolipid galactocerebroside (GCB).

We investigated the reaction of GCB with $\mathrm{NO}_{3} \bullet$ both as a pure monolayer and in a mixed monolayer with the saturated and thus less reactive PA as a pair of proxies for marine aerosol monolayers containing lipopolysaccharides. A mixed monolayer of GCB and the unsaturated analogue of PA, palmitoleic acid (POA), was also oxidised in order to test how the introduction of a double bond affects the interaction between GCB and the fatty acid. Unlike saturated PA that is only subject to slow hydrogen abstraction [23,39], the double bond in POA reacts quickly with $\mathrm{NO}_{3} \bullet$ [39], so this system should behave rather differently.

A 2013 study [41] found that the PA/GCB film mixture is fully miscible and that the components are attracted to each other and produce an enhanced film stability as a mixture, and also found that $\mathrm{Ca}^{2+}$ and, to a lesser extent, $\mathrm{Mg}^{2+}$ cations in the subphase increase acyl chain ordering. In order to investigate whether this has any effect on the oxidation, we used both pure water and $\mathrm{CaCl}_{2}$ solution subphases.

Based on the results mentioned above with regards to the stability of the GCB/PA mixture and the lack of a double bond for fast oxidation in PA, we expected that at least part of the GCB/PA monolayer would remain at the surface after oxidation. The fate of the pure GCB monolayers will depend on whether any product from the reaction is sufficiently surface active to remain partitioned to the interface.

\section{Experiments}

\subsection{Neutron Reflectivity (NR)}

This research was performed on the specular neutron reflectometry instrument INTER at the ISIS Neutron and Muon Source. A comprehensive summary of the use of neutron reflectometry for the study of organic films at the air-water interface was provided by a review paper by Lu et al. in 2000 [44], which details the physics of neutron reflectivity and the mathematical manipulations required to convert reflectivity data into coverage data using fitting models. In short, specular NR typically determines the thickness, density, and roughness of thin layers stacked in the out-of-plane direction of a flat sample. In the present work, the only quantity extracted was the time evolution of the surface coverage of deuterated moieties that were present in the system. Purely hydrogenous moieties do not contribute to the NR signal, however the relative change in their coverage (as well as that of deuterated moieties) was monitored by simultaneous IRRAS. Since 2000, the number of models and methods for dealing with this data has increased significantly, and a recent paper by Campbell et al. [45] provides a review of the existing methods and an optimum model validation. The brief section that follows here will give a simplified introduction to the technique from a physical perspective and will only focus on the techniques and models required for a simple monolayer system (also see our recent method paper for further details [46]). More complex physical systems naturally require more complex modelling approaches that are not covered here.

The intensity of the reflected neutron beam depends on the differences between concentrations of nuclei with different neutron scattering lengths in the layers of the material stacked in the $z$-direction 
(vertical). Simplifications of the complex equations that govern the relationship between neutron wavelength and reflected intensity are possible when investigating just one layer (for instance, an organic monolayer) at the air-water interface. This is because air has such a low number density of atoms that it essentially has a scattering length density of zero and an "air-contrast matched" or "null-reflecting" water subphase with a scattering length density of zero can be prepared by mixing $\mathrm{D}_{2} \mathrm{O} 8.8 \% v / v$ in $\mathrm{H}_{2} \mathrm{O}$ such that the surfactant at the air-water interface is the only component with a non-zero scattering length density.

According to the simplified equation that applies for this system (a single monolayer at the interface between air and a null-reflecting subphase), the reflectivity, $R$, varies as a function of the energy of the incident neutrons (expressed as momentum transfer, $Q$, and measured by white-beam time-of-flight) and the scattering length density, $\rho$, and thickness, $\tau$, of the monolayer according to the following equation:

$$
\frac{Q^{4} R}{16 \pi^{2}} \cong 4 \rho^{2} \sin ^{2} \frac{Q \tau}{2}
$$

The layer thickness and scattering length density for the system can then be inferred from the relationship between the reflectivity and momentum transfer measured. These two parameters cannot be fitted independently (as they are multiplicatively dependent), however instead they must be fitted as a combined $\rho \tau$ variable, which corresponds to a surface concentration of scattering length, from which the surface concentration, or "coverage", $\Gamma$, of the relevant surfactant species can be determined (as the scattering lengths, $b$, of the species are known):

$$
\Gamma=\frac{\rho \tau}{b}
$$

If multiple components are deuterated, however only one is being considered possibly reactive (as in the GCB/PA systems studied), then a contribution to $\rho \tau$ attributed to a known initial amount of the unreactive co-surfactant (PA) must be accounted for in converting a fitted $\rho \tau$ for the system to a $\Gamma$ value specific to the surfactant of interest $(\mathrm{GCB})$ :

$$
\Gamma_{\mathrm{GCB}}=\frac{\rho \tau-\Gamma_{\mathrm{PA}} b_{\mathrm{PA}}}{b_{\mathrm{GCB}}}
$$

Reflectivity curves of $Q$ vs. $R$ are collected at intervals of $20 \mathrm{~s}$ throughout the reaction and each curve is fitted using MOTOFIT [47], an extension to the Igor Pro data manipulation and visualisation environment, to produce values for surface coverage at 20-s time intervals. These coverage values have the advantage of being absolute and, thus, are comparable between experiments as well as within one experiment (the latter alone is the case for IRRAS).

In order to achieve measurable scattering length density contrasts between the subphase and monolayer, the film components of interest for each experiment were deuterated to give a high positive scattering length density. Specifically, $18.2 \mathrm{M} \Omega \mathrm{cm}$ water with $\mathrm{D}_{2} \mathrm{O}$ from Sigma Aldrich $(99.9 \%$ atom D) and $\mathrm{CaCl}_{2}$ from Fisher Scientific (General Purpose Grade) was used to prepare null-reflecting water and $0.1 \mathrm{M} \mathrm{CaCl}_{2}$ null-reflecting solution subphases. Of the two tail chains that were present in GCB, the saturated chain was deuterated by Avanti Lipids in a custom synthesis specifically for the present study to produce $d$-GCB. Deuteration of the unsaturated chain is more synthetically complicated and was not feasible within our timeframe and budget. $d_{31}$-PA was acquired from Sigma Aldrich $(98 \%$ atom D; $99 \%$ ). Hydrogenous GCB ( $\geq 97 \%)$, PA ( $\geq 99 \%)$, and POA ( $\geq 98.5 \%$ ) were also acquired from Sigma Aldrich. All film components were spread from dilute $\mathrm{CHCl}_{3}$ solutions, with $\mathrm{CHCl}_{3}$ acquired from Sigma Aldrich (99.4\%) using a $50 \mu \mathrm{L}$ spade-ended Hamilton syringe.

The GCB used (both deuterated and hydrogenated) was a mixture of NFA (non-hydroxylated fatty acid) and HFA (hydroxylated fatty acid) forms and, thus, $d$-GCB is a mixture of $d_{31}$-(NFA)GCB and $d_{30}$-(HFA)GCB (see Figures 1 and 2 for details). 
(HFA)GCB

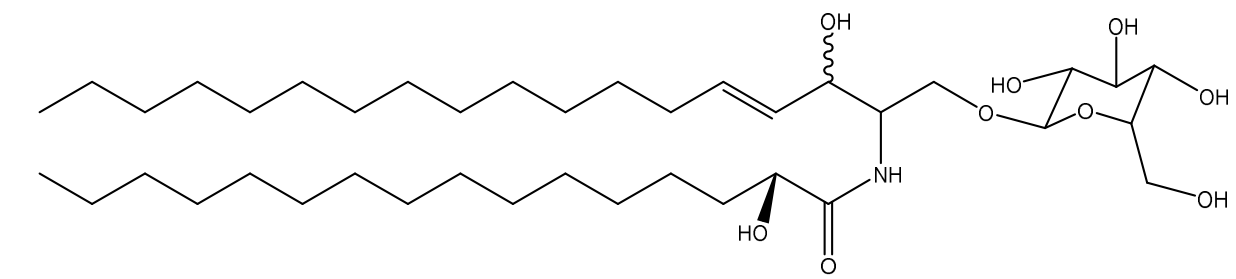

(NFA)GCB<smiles>CCCCCCCCCCCCC/C=C/[C@H](O)C(COC1C(O)C(O)C(O)C(O)C1O)NC(=O)CCCCCCCCCCCCCCCCC</smiles>

$\mathrm{d}_{30}-(\mathrm{HFA}) \mathrm{GCB}$

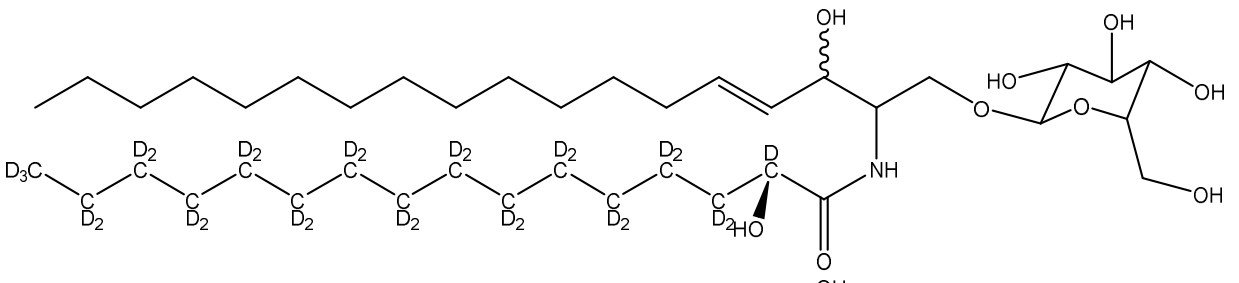

$\mathrm{d}_{31}-(\mathrm{NFA}) \mathrm{GCB}$

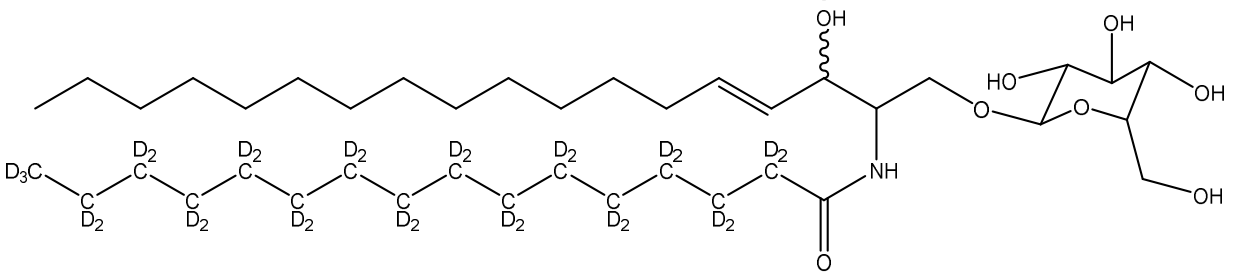

Figure 1. Molecular structures of the galactocerebroside (GCB) species employed; the deuterated GCB species were custom-synthesised for the present study.

PA<smiles>CCCCCCCCCCCCCCCC(=O)O</smiles>

$\mathrm{d}_{31} \mathrm{PA}$<smiles>CC(C)(C)OCCCCCCCCCCCCCCC(=O)O</smiles>

POA<smiles>CCCCCC/C=C/CCCCCCCC(=O)O</smiles>

Figure 2. Molecular structures of the fatty acid species employed in the present study.

Due to the need to spread from a $\mathrm{CHCl}_{3}$ solution (in which GCB is sparingly soluble) rather than the more convenient $\mathrm{CHCl}_{3} / \mathrm{CH}_{3} \mathrm{OH}$ solution (in which $\mathrm{GCB}$ is much more soluble), in order to achieve reliable monolayer production (the mixed chloroform/methanol solution may not evaporate evenly from the interface and could leave methanol behind in the system which would not be at all realistic as an atmospheric proxy) and considering the need to spread only a small volume $(<100 \mu \mathrm{L})$ of solution in order to ensure rapid evaporation of the carrier solvent, we spread from a saturated solution of GCB, for which the analysis of the NR data gave a concentration of $\sim 1 \mathrm{mg} \mathrm{mL} L^{-1}$. This corresponded to an area per molecule of $\sim 30 \mathrm{~A}^{2}$, and a surface pressure of $\sim 25 \mathrm{mN} \mathrm{m}^{-1}$. 


\subsection{Fourier Transform Infra-Red Reflection Absorption Spectroscopy (IRRAS)}

The integration of in situ Fourier transform infra-red reflection absorption spectroscopy (IRRAS) is logistically complex and makes use of a bespoke reaction and analysis chamber developed by us. This equipment and the setup that was required for conducting these experiments is laid out in detail in a method paper [46]. The general setup for this experiment aligns with that in the method paper apart from where specifically noted. The FTIR spectrometer that was used was a Thermo-Nicolet iS50. We used a purpose-built gas flow cell (volume: ca. $1.5 \mathrm{~L}$ ) containing a liquid trough $(238 \mathrm{~mm} \times$ $70 \mathrm{~mm}$ ) and two $\mathrm{CaF}_{2}$ windows (CrysTran) of $1.5 \mathrm{~mm}$ thickness to allow ingress and egress of the IR light. The windows were mounted at an angle of $48^{\circ}$ with respect to the vertical to enable normal or near-normal incidence for the IR beam in an angular range of 42 to $55^{\circ}$. A third circular quartz window was mounted above the centre of the liquid trough to allow the height laser to monitor the liquid surface. This window was tilted by $5^{\circ}$ from the horizontal in order to avoid a secondary reflection into the height laser. The neutron beam entered and exited the chamber though rectangular quartz windows $(50 \mathrm{~mm} \times 68 \mathrm{~mm})$ at either end of the reaction chamber.

Baseline-corrected integrations under $\mathrm{CH}$ and $\mathrm{CD}$ peaks (a symmetric and asymmetric stretch for each, typically $2110-2070 \mathrm{~cm}^{-1}$ and $2208-2178 \mathrm{~cm}^{-1}$ for CD bonds and $2868-2833 \mathrm{~cm}^{-1}$ and $2945-2898$ $\mathrm{cm}^{-1}$ for $\mathrm{CH}$ bonds, though small surface interaction effects may cause a slight chemical shift in the location of these bands in some cases) provide a series of peak area against time traces for each reaction, which reflects the presence or absence of $\mathrm{CH}$ or $\mathrm{CD}$ chains at the surface and follows their evolution throughout the reaction. Due to the IRRAS geometry deployed, the peaks are inverted in the Fourier-transformed spectra, appearing as regions of depressed absorbance. This means that the baseline-corrected integrated peak areas are negative.

The absolute intensity values of these absorbance bands vary significantly between experiments due to slight changes in the geometry of the focusing setup, so no absolute coverage data can be determined from any one experiment. The IRRAS data are strictly semi-quantitative: they allow the inference of trends in the concentration of $\mathrm{CH}$ and $\mathrm{CD}$ bonds at the surface across one experiment, however not absolute determination of surface concentrations for any one run or meaningful comparisons of concentrations between experiments. The asymmetric stretches are habitually stronger than the symmetric stretches (particularly for $\mathrm{CH}$ bonds) in these spectra due to complex quantum chemistry effects that are not the subject of the current study. The shift of the CD stretches to much lower wavenumber ranges than the $\mathrm{CH}$ stretches is due to the larger reduced mass of the bonding interaction given the greater mass of the deuterium nucleus.

\subsection{Physical Setup and Gas Handling}

$\mathrm{NO}_{3} \bullet$ was produced as described previously by Sebastiani et al. [39] through a gas flow system by the reaction of an excess of $\mathrm{NO}_{2}$ (Scientific and Technical Gases Ltd.; $1000 \mathrm{ppm}$ in air $\pm 2 \%$ ) with $\mathrm{O}_{3}$ in a $5 \mathrm{~L}$ reaction bulb. $\mathrm{O}_{3}$ was generated from $\mathrm{O}_{2}$ (BOC; $99.999 \%$ ) using a pen-ray ozoniser (model: SOG-2; Ultra-Violet Products Ltd., Cambridge, UK). An equilibrium mixture of the gases $\mathrm{NO}_{2}, \mathrm{NO}_{3} \bullet$, and $\mathrm{N}_{2} \mathrm{O}_{5}$ (in a stream of $\mathrm{O}_{2}$ ) was established and then fed into the reaction chamber. The $\mathrm{O}_{2}$ flow was kept constant at $1.2 \mathrm{~L} \mathrm{~min}^{-1}$, and the $\mathrm{NO}_{2}$ flow could be adjusted to achieve the desired $\left[\mathrm{NO}_{3} \bullet\right.$ ] for each experiment. $\left[\mathrm{NO}_{2}\right]$ was kept in large excess for all conditions to ensure that $\mathrm{O}_{3}$ was consumed well before the gas mixture entered the reaction chamber. In previous work, we have shown that $\mathrm{NO}_{2}$ does not remove organic films from the air-water interface on timescales relevant to our experiments, however it is able to slowly isomerise carbon-carbon double bonds [48]. All plots for the reactions were time-normalised so that $t=0 \mathrm{~s}$ refers to the point at which oxidant gas was admitted from the mixing bulb holding the equilibrium mixture through a short polytetrafluoroethylene (PTFE) tube into the reaction chamber. This equipment was located within the INTER blockhouse so that the neutron beam had to be blocked with shutters in order to allow the safe ingress and egress of personnel when starting the reaction. As a result, a few of the 20-s time interval data points were always missing from 
either side of the start of the reaction. Other gaps in the NR data stem from occasional short-term beam loss at the neutron facility.

\subsection{Offline Brewster Angle Microscopy (BAM) with Surface Tension Measurements}

Film characterisation for GCB on water, GCB/PA on water, and GCB/PA on an aqueous solution containing $\mathrm{CaCl}_{2}$ was performed using a Langmuir trough with moveable barriers and a Wilhelmy plate surface pressure measurement system driven by a NIMA IU4 serial interface in order to provide a visual assessment of the nature of the film with a Brewster angle microscope (BAM)-which is particularly interesting for the mixed films-as well as a pressure-area isotherm for the system.

The BAM technique allows the direct observation of ultrathin organic films on transparent dielectric substrates. It is based on the effect that from the clean surface no reflection occurs for $p$-polarized incoming light under the Brewster angle. The technique allows the characterisation of morphological features of monolayers during compression/decompression. Brewster angle microscopy images at characteristic phase transitions of the surface pressure-area isotherm give valuable information on the structural and orientational changes in the monolayer. For instance, the conformation of unsaturation, such as cis or trans, induces observable differences in domain morphology of fatty acids of the same length. Here, we use the BAM images in a qualitative way, e.g., to demonstrate the effect of $\mathrm{Ca}^{2+}$ ions in the subphase on the monolayer morphology.

These monolayers were prepared in the same manner as the films that were used for the neutron reflectometry and IRRAS measurements. The Brewster angle microscope and associated Langmuir trough were made available at the Diamond Light Source. The microscope that was used was an Accurion Nanofilm EP ${ }^{3}-096$ ellipsometer and BAM operated with the $\mathrm{EP}^{3}$ control software. The Langmuir trough was a NIMA DLS1140 with a variable surface area of between $700 \mathrm{~cm}^{2}$ and $\sim 70 \mathrm{~cm}^{2}$ (the minimum surface area is limited by the type of barriers used due to the proximity of the BAM objective lens) - a compression ratio of $\sim 10$. Due to a small flaw in the objective lens, a banding artefact can be observed in some images. This can normally be corrected by subtracting a clean surface background image from the film images, however, if the brightness of the sample film is substantially different to the brightness of a clean water surface so that images of the two cannot be gathered with the same gain settings, as is the case for the GCB/PA on water system, then this correction is not possible. However, for the cases when this occurred for images that were taken as part of the present study, we believe that the film surface features are on a sufficiently different scale to be visually differentiable from the banding artefact.

All neutron reflectivity, infra-red spectroscopy, and microscopy raw data is available in a data repository (Woden et al., 2018) [49].

\section{Results and Discussion}

\subsection{BAM Film Characterisation}

Figure 3 shows a film of GCB on the surface of a pure water subphase. The strong acyl chain van-der-Waals interactions between the GCB molecules cause them to form islands (of less than ca. $15 \mu \mathrm{m})$ at low surface pressures. As the surface pressure increases, the film spreads to cover the surface more evenly.

Figure 4 shows a film of a GCB/PA (1:1 w/w) monolayer on the same subphase. Due to the BAM setup discussed in the methods section and the unusually bright nature of this film, these pictures are affected by a banding artefact that cannot be fully suppressed with background correction. For similar reasons related to the different gain settings required to gather this set of images, no conclusions can be drawn by comparing the absolute brightness of these images to that of those in Figure 3. What can be determined, however, is that a situation similar to that observed for the pure GCB monolayer, in which islands can be seen at low surface pressures (up to $\sim 10 \mathrm{mN} \mathrm{m}^{-1}$ ) which are not seen at higher 
pressures, holds for this mixed system as well. The effect is weaker than for pure GCB, however is still observed here.
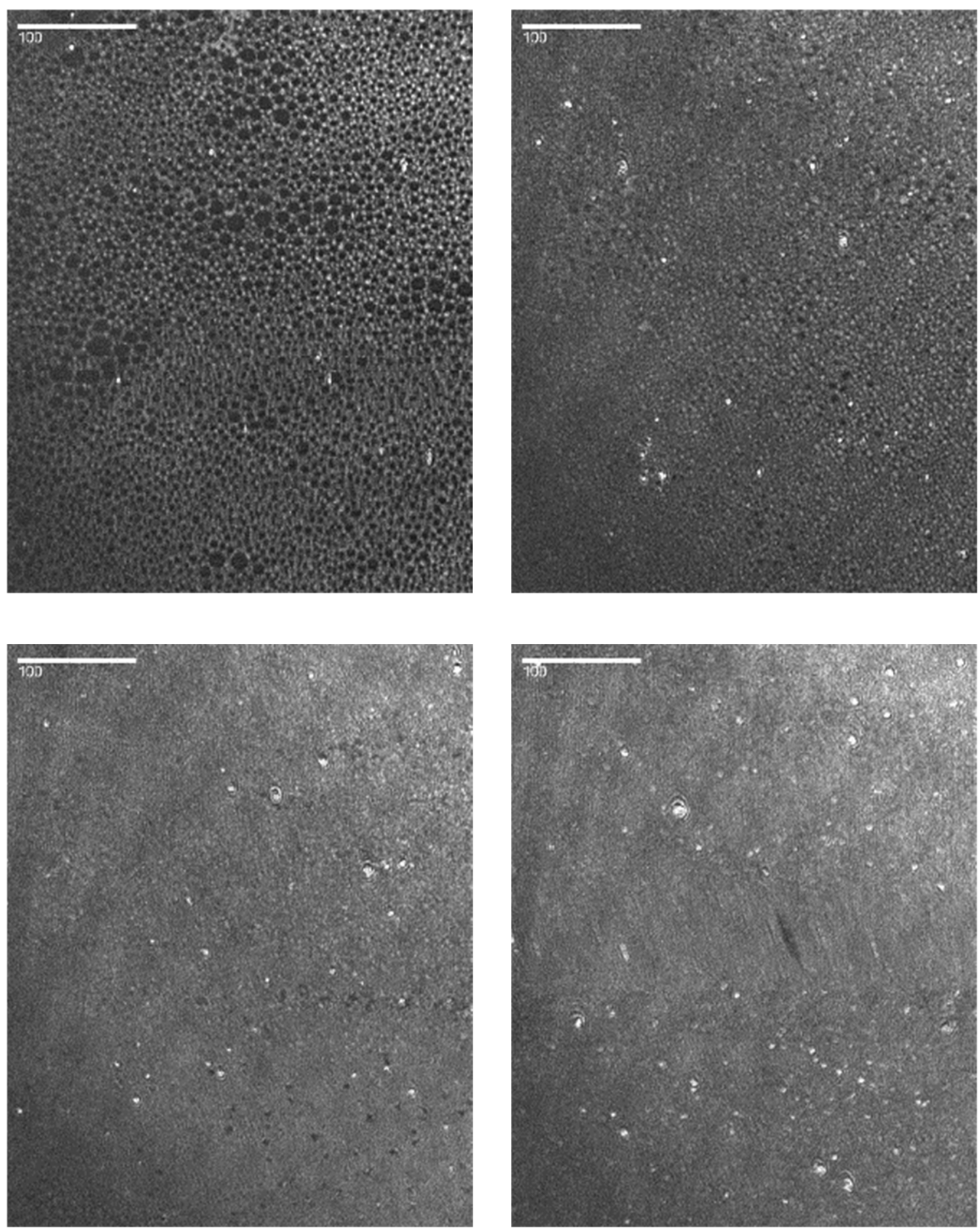

Figure 3. BAM images of a GCB monolayer on water at various surface pressures—scale bar represents $100 \mu \mathrm{m}$; top left, top right, bottom left, bottom right: $1,5,10,25 \mathrm{mN} \mathrm{m}^{-1}$. 

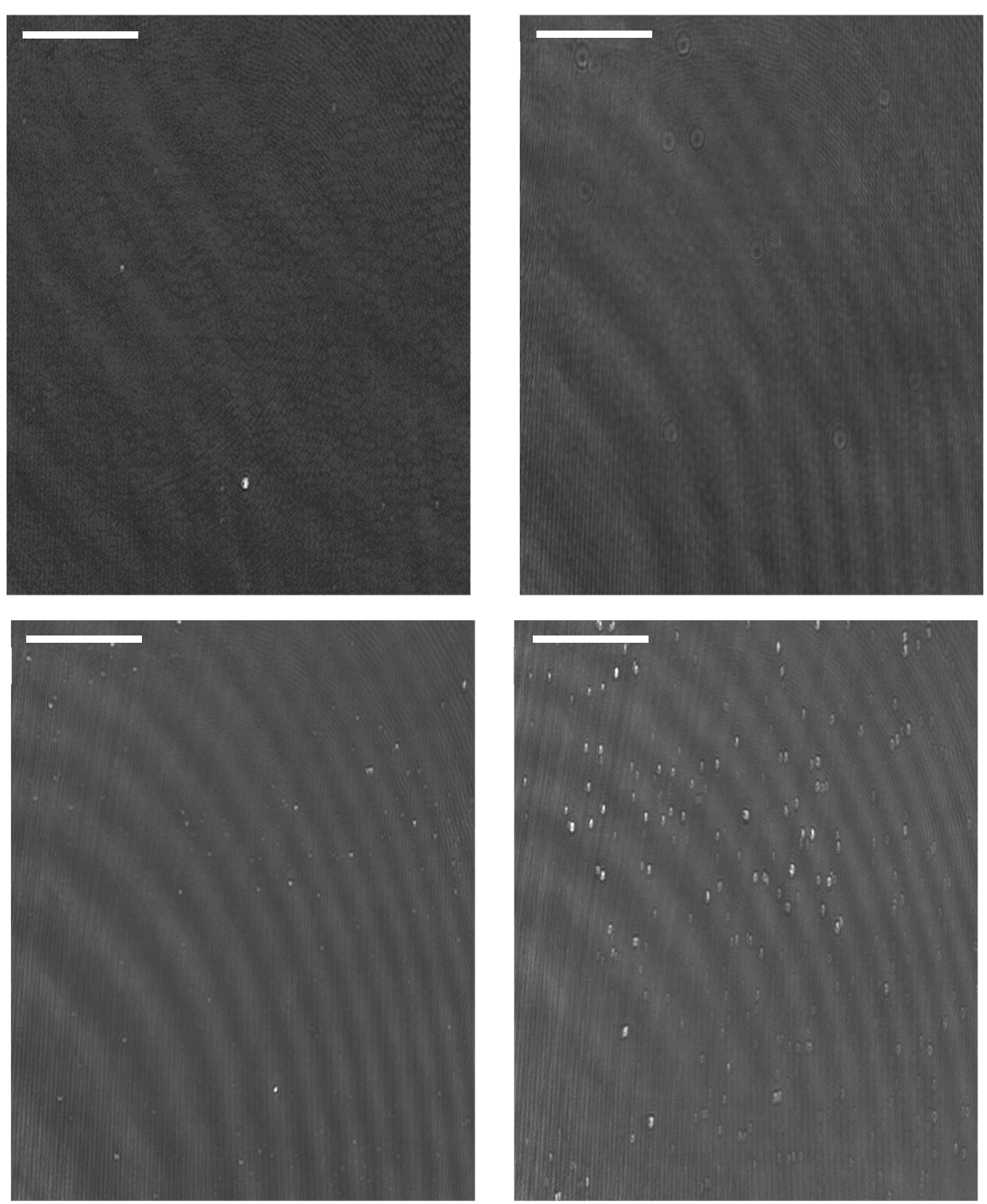

Figure 4. BAM images of a two component (GCB/palmitic acid (PA)) monolayer on water at various surface pressures—scale bar represents $100 \mu \mathrm{m}$; top left, top right, bottom left, bottom right: 1, 5, 10, $25 \mathrm{mN} \mathrm{m}^{-1}$.

Figure 5 shows the same film composition as Figure 4, but now on $100 \mathrm{mM} \mathrm{CaCl}_{2}$ (aq) instead of pure water. Here, the formation of islands at low surface pressures is much less pronounced, with only a slight mottling showing. This is in line with the observation by Adams and Allen [41] that $\mathrm{Ca}^{2+}$ ions stabilise this mixed film through cross-chain interactions. 

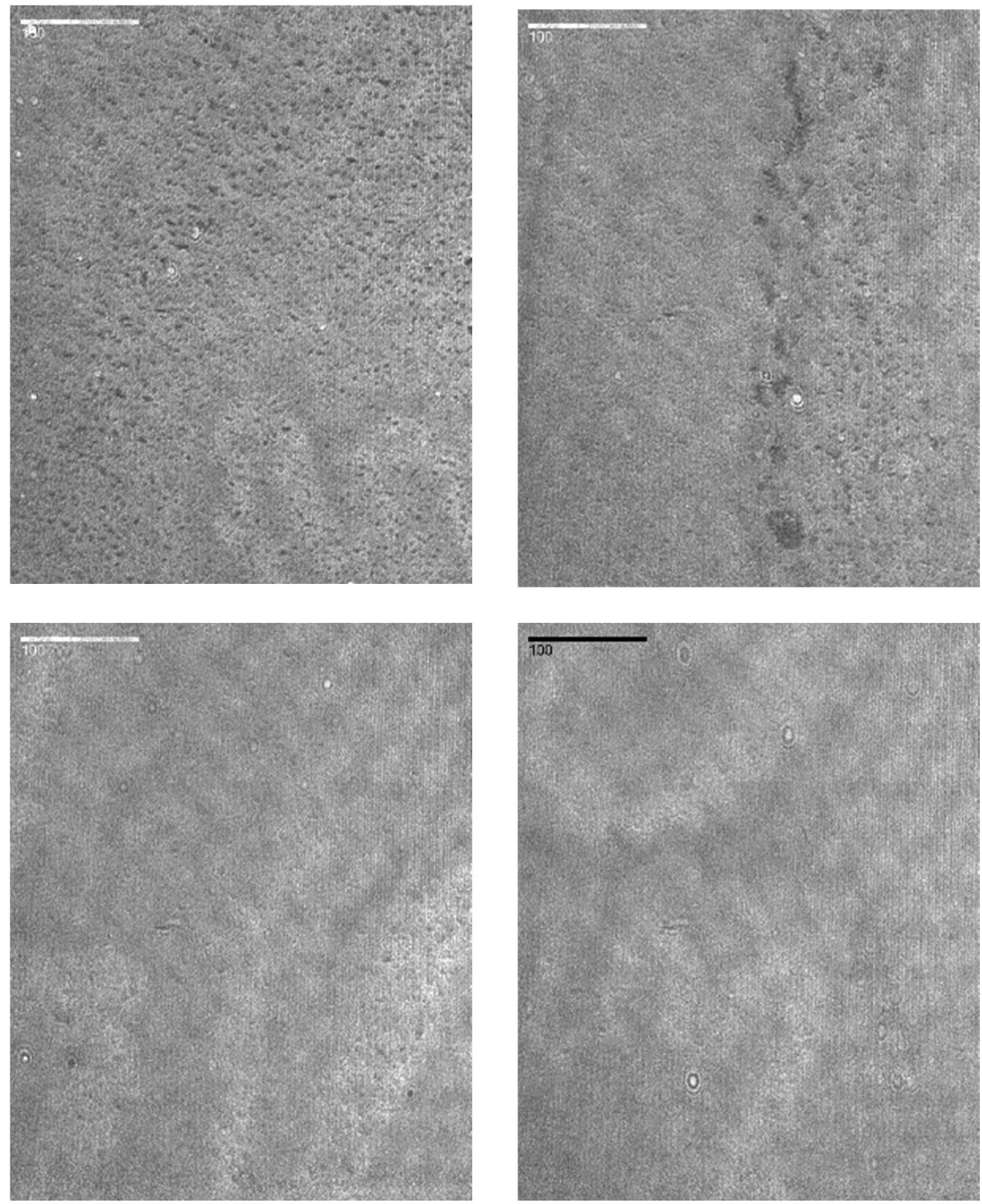

Figure 5. BAM images of a two component (GCB/PA) monolayer on $\mathrm{CaCl}_{2}(\mathrm{aq} ; 100 \mathrm{mM})$ at various surface pressures—scale bar represents $100 \mu \mathrm{m}$; top left, top right, bottom left, bottom right: 1, 5, 10, $25 \mathrm{mN} \mathrm{m}^{-1}$.

\subsection{Single Component (GCB) Monolayer Oxidation}

Figure 6 shows both neutron reflectometry (NR) and IRRAS data from the oxidation of a GCB film on pure water. The injection of $\mathrm{NO}_{3} \bullet$ into the reaction chamber at $t=0 \mathrm{~s}$ does not have a noticeable effect on the NR signal (see black symbols and left ordinate). A reflectivity signal in keeping with what was observed at the start of the reaction still remains at the end (the data gap is due to beam down time). It should be noted that this does not mean that no reaction has taken place. The measured neutron signal is only sensitive to the deuterated part of the molecule (i.e., the saturated chain in our case). A reaction at the double bond that removes the unsaturated tail chain from the GCB molecule 
is consistent with this neutron signal. The complementary IRRAS data support this hypothesis, as detailed below.

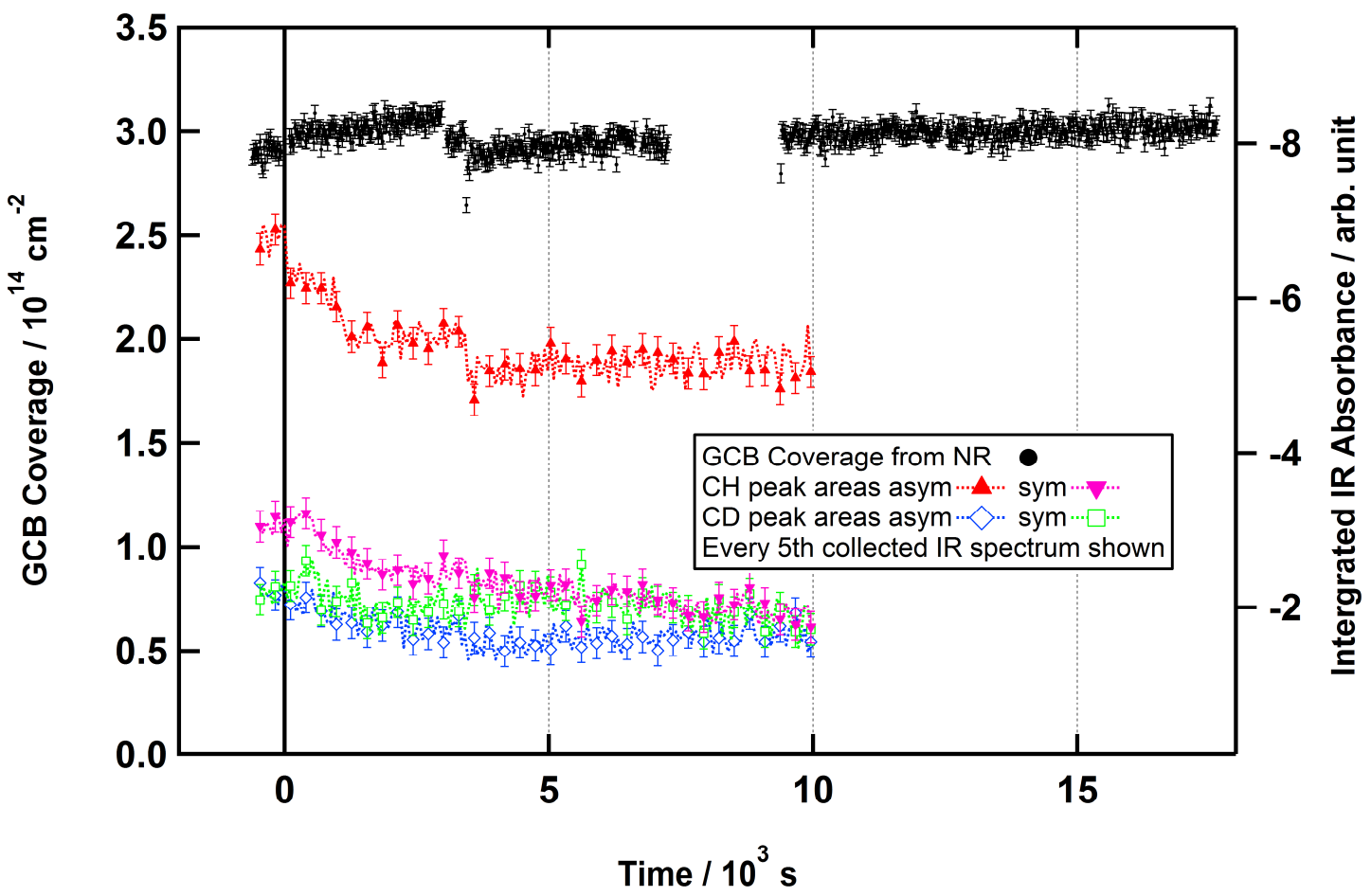

Figure 6. Oxidation of a GCB monolayer on pure water-neutron reflectometry (NR) (black circles and left ordinate) and infra-red reflection absorption spectroscopy (IRRAS) (coloured symbols and right ordinate) data as a function of time. We spread a monolayer of $\sim 6.5 \times 10^{-5} \mathrm{~L}_{\text {from a } \sim 1 \mathrm{~g} \mathrm{~L}^{-1}}$ spreading solution of $d$-GCB in $\mathrm{CHCl}_{3}$. $\mathrm{NO}_{3} \bullet$ was admitted at $t=0 \mathrm{~s}$ at a concentration of $\sim 4.4 \times$ $10^{9} \mathrm{~cm}^{-3}$. The integrated absorbance areas for the IRRAS data were calculated for $2110-2070 \mathrm{~cm}^{-1}$ and $2208-2178 \mathrm{~cm}^{-1}$ for CD bonds (one symmetric and one asymmetric stretch; coloured squares and diamonds) and for $2868-2833 \mathrm{~cm}^{-1}$ and $2945-2898 \mathrm{~cm}^{-1}$ for $\mathrm{CH}$ bonds (one symmetric and one asymmetric stretch; coloured triangles).

IRRAS data (shown as coloured symbols in Figure 6) were collected simultaneously with the neutron data. The IRRAS data run only to around 10,000 s (a little short of $3 \mathrm{~h}$ ) because movement of the position of the interface due to evaporation makes the IRRAS data unusable due to increasingly poor focussing of the IR beam. This evaporation effect is corrected for in the case of the NR data by continuously reading the location of the air-water interface with a height laser and adjusting the position of the experimental stage upwards to ensure that the NR data remains unaffected. Unfortunately, for technical reasons and due to space limitations at the beamline sample area, the movement of the experimental stage also moves the IRRAS assembly upwards so that the IRRAS signal cannot be recovered from the effects of interfacial drift in this way (the IRRAS signal can only be brought back into focus by manually adjusting the trough height which would lead to the loss of the NR data). However, neutron reflectometry data were collected for a $5 \mathrm{~h}$ period for this system, and no significant NR signal reduction was seen over this period (the NR signal varied by a maximum of $10 \%$ ), as can be seen in Figure 6.

The simultaneous IRRAS data in Figure 6 show that the CD signal remains constant within experimental error, which is in line with the neutron data in Figure 6, however the $\mathrm{CH}$ signal does show a reduction over time, which is consistent with an oxidation reaction taking place at the double bond on the hydrogenous chain that would be invisible when relying on NR data alone. A significant $\mathrm{CH}$ signal remains, however, which suggests that some hydrogenous material is retained at the air-water interface together with the entire deuterated chain. 
Oxidations of GCB monolayers were also carried out on a $\mathrm{CaCl}_{2}$ (aq) subphase. This did not seem to have an effect on the reaction within experimental uncertainties. The NR and IRRAS data showed very similar patterns to the pure water case, except that the $\mathrm{CH}$ signal dropped significantly more (by around 50\%) in the salt subphase case. This data is available in the repository (Woden et al., 2018) [49].

\subsection{Two Component (GCB/PA) Monolayer Oxidation}

To provide a model for cerebrosides distributed in marine aerosols more generally, and to investigate the effects of the attractive surface interaction between PA and GCB described by Adams and Allen [41] on the oxidation, mixed monolayers of $d_{31}$-PA and $d$-GCB (1:1 mass ratio) were prepared and oxidised by $\mathrm{NO}_{3} \bullet$ in the same manner as were the pure $d$-GCB monolayers. In this case, the neutron reflectometry was sensitive to the deuterated portion of $d$-GCB and to $d_{31}$-PA, and IRRAS was sensitive to these in the $\mathrm{CD}$ band and additionally to the hydrogenous portion of $d-\mathrm{GCB}$ in the $\mathrm{CH}$ band.

Figure 7 shows the neutron reflectometry data for this oxidation (black circles and left ordinate), and no significant reduction in the NR signal is observed. PA does not have a double bond and so is not susceptible to rapid attack by $\mathrm{NO}_{3} \bullet$ as are unsaturated species, therefore it would not be expected to react quickly on the timescales of our experiment (compare the stability of stearic acid monolayers to $\mathrm{NO}_{3} \bullet$ recently reported by Sebastiani et al. [39]). The lack of any change in neutron reflectometry signal indicates that, as in the case of the single component GCB monolayer, the deuterated (saturated) chain remains at the surface.

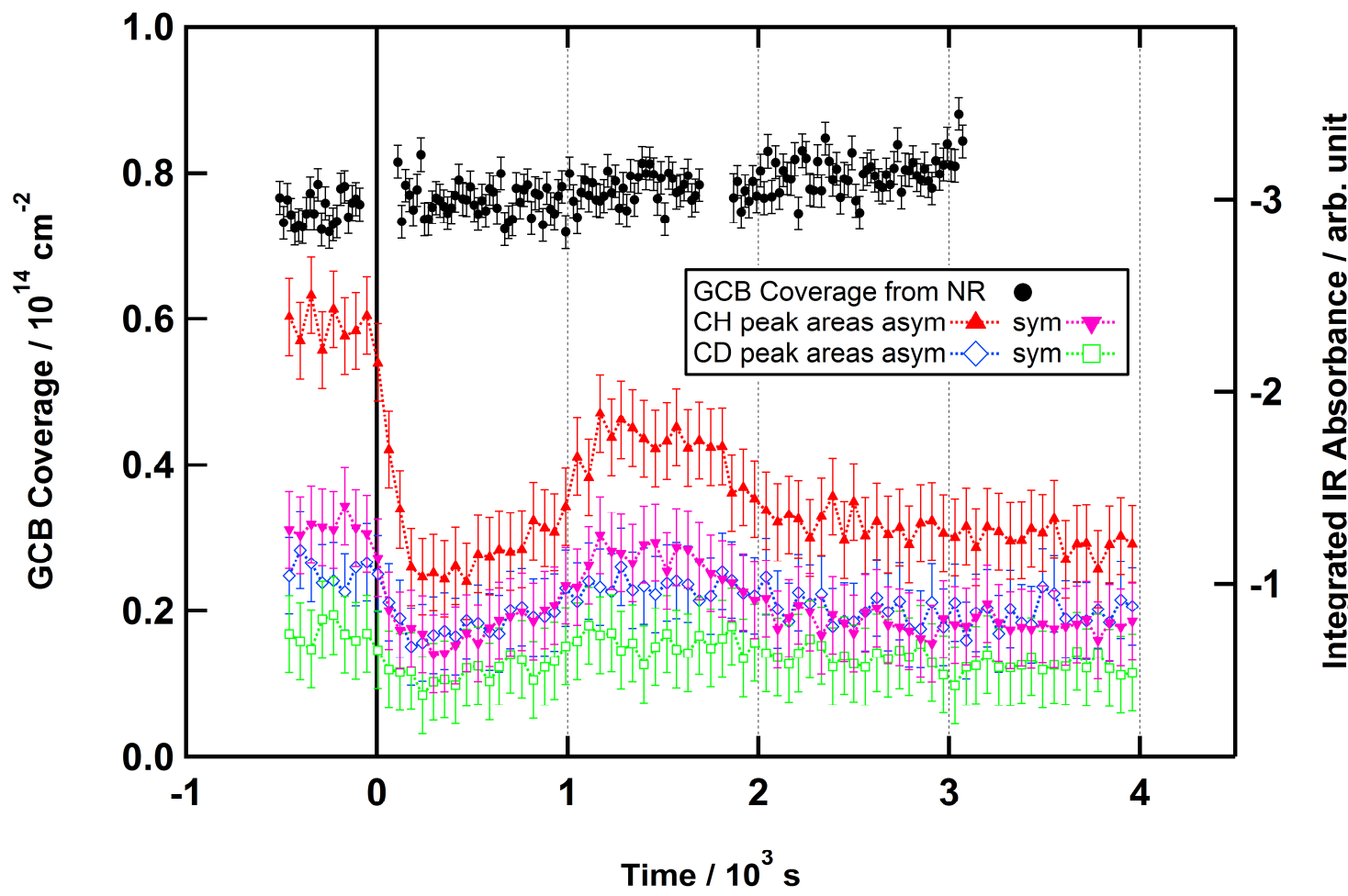

Figure 7. Oxidation of a two component (GCB/PA) monolayer on pure water-NR (black circles and left ordinate) and IRRAS (coloured symbols and right ordinate) data as a function of time. We spread a monolayer of $\sim 6.5 \times 10^{-5} \mathrm{~L}$ from a spreading solution containing $\sim 0.5 \mathrm{~g} \mathrm{~L}^{-1}$ of $d$-GCB and $\sim 0.5 \mathrm{~g} \mathrm{~L}^{-1}$ of $d$-PA in $\mathrm{CHCl}_{3} . \mathrm{NO}_{3} \bullet$ was admitted at $t=0 \mathrm{~s}$ at a concentration of $\sim 4.4 \times 10^{9} \mathrm{~cm}^{-3}$. The integrated absorbance areas for the IRRAS data were calculated for $2110-2070 \mathrm{~cm}^{-1}$ and $2208-2178 \mathrm{~cm}^{-1}$ for $\mathrm{CD}$ bonds (one symmetric and one asymmetric stretch coloured squares and diamonds) and for $2868-2833 \mathrm{~cm}^{-1}$ and $2945-2898 \mathrm{~cm}^{-1}$ for $\mathrm{CH}$ bonds (one symmetric and one asymmetric stretch; coloured triangles). 
The simultaneous IRRAS data for this reaction (shown in Figure 7 as coloured symbols) also show a similar pattern to the GCB monolayer oxidation. The CD peak areas remain constant within experimental error, whereas the $\mathrm{CH}$ peak areas decline over the course of the reaction, however do not disappear entirely. The trend is not as clear as for the single component GCB monolayer (after the initial reaction, the peak areas rise slightly again before falling back to their final values), which we attribute to the fact that the GCB/PA system will be rearranging at the air-water interface as the oxidation of the double bond in the hydrogenous GCB tail chain occurs. The IRRAS signal is sensitive to the orientation of molecules at the interface, so some variation due to rearrangements during the reaction is not unexpected.

These data suggest overall that the behaviour of the two component (GCB/PA) monolayer during $\mathrm{NO}_{3} \bullet$-initiated oxidation is similar to that of the single component (GCB) monolayer. PA is unreactive, and the double bond in the unsaturated chain of GCB is attacked by the $\mathrm{NO}_{3} \bullet$, leaving part of that chain and the rest of the molecule (head and saturated chain) at the surface. The longest oxidation carried out for the two-component (GCB/PA) monolayer was $3 \mathrm{~h}$, with a maximum of $15 \%$ signal variation during the run (no consistent trend, just variation in signal probably due to rearrangements at the air-water interface). These additional data are available in the repository (Woden et al., 2018) [49].

Adams and Allen [41] reported increased stability for these mixed monolayers with $\mathrm{Ca}^{2+}$ in the subphase. We therefore tested oxidation on a $\mathrm{CaCl}_{2}$ solution subphase as well.

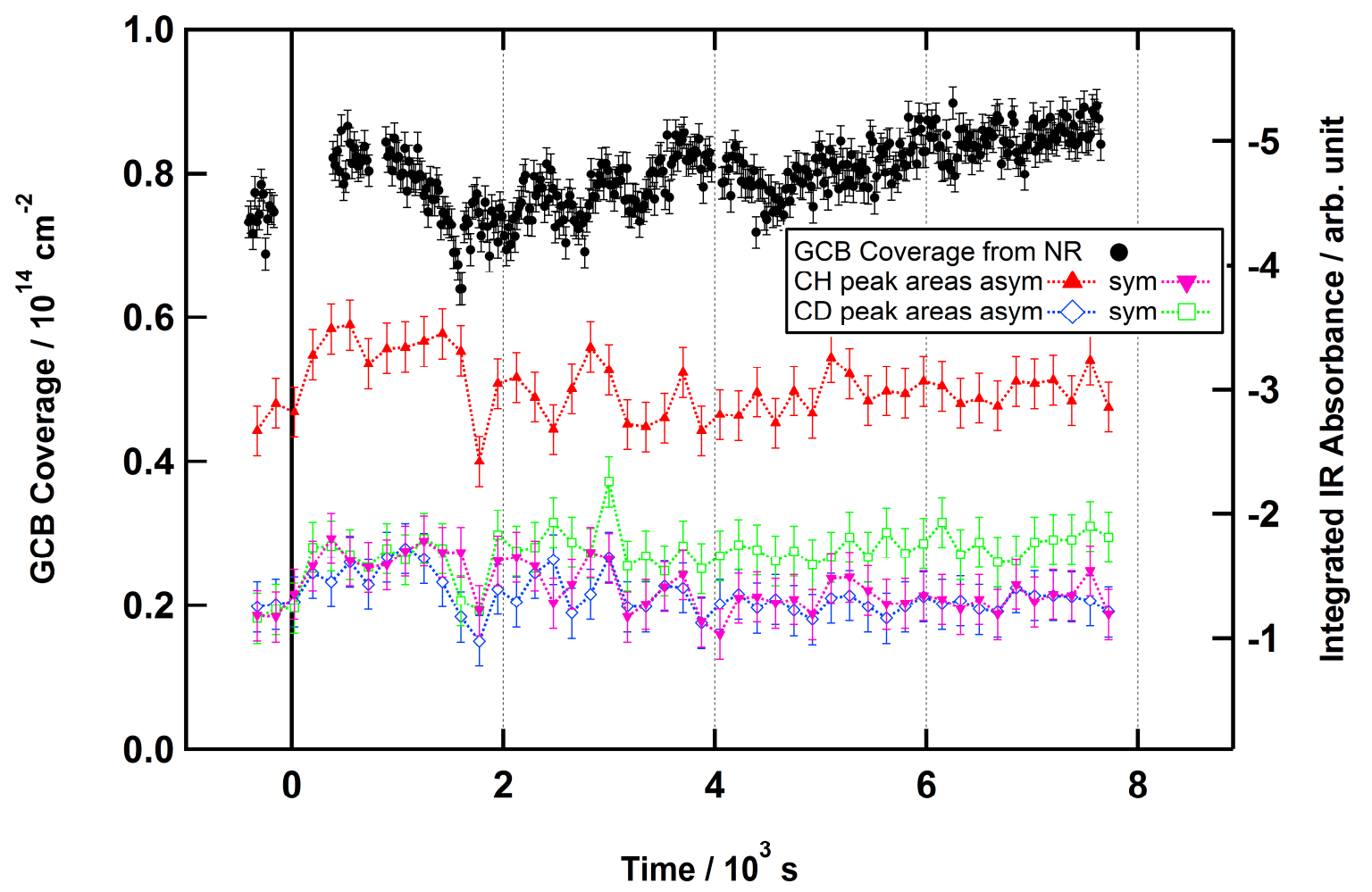

Figure 8. Oxidation of a two component (GCB/PA) monolayer on $\mathrm{CaCl}_{2}$ aqueous solution-NR (black circles and left ordinate) and IRRAS (coloured symbols and right ordinate) data as a function of time. We spread a monolayer of $\sim 6.5 \times 10^{-5} \mathrm{~L}$ from a spreading solution containing $\sim 0.5 \mathrm{~g} \mathrm{~L}^{-1}$ of $d$-GCB and $\sim 0.5 \mathrm{~g} \mathrm{~L}^{-1}$ of $d$-PA in $\mathrm{CHCl}_{3}$. $\mathrm{NO}_{3} \bullet$ was admitted at $t=0 \mathrm{~s}$ at a concentration of $\sim 4.4 \times$ $10^{9} \mathrm{~cm}^{-3}$. The integrated absorbance areas for the IRRAS data were calculated for $2110-2070 \mathrm{~cm}^{-1}$ and $2208-2178 \mathrm{~cm}^{-1}$ for CD bonds (one symmetric and one asymmetric stretch coloured squares and diamonds) and for $2868-2833 \mathrm{~cm}^{-1}$ and $2945-2898 \mathrm{~cm}^{-1}$ for $\mathrm{CH}$ bonds (one symmetric and one asymmetric stretch; coloured triangles).

Figure 8 shows the neutron reflectometry data for oxidation in the presence of $\mathrm{Ca}^{2+}$ in the subphase (black circles and left ordinate) and, although a signal oscillation can be seen which likely indicates 
surface reorganisation (the formation of domains at the surface can cause inaccuracies in the calculation of surface coverage by a uniform monolayer model as reported by Lu et al. [44]), there is no general trend up or down, suggesting that, once again, the saturated part of GCB and the PA component remain at the surface after oxidation. Simultaneous IRRAS data (shown in Figure 8 as coloured symbols) demonstrate a similar signal variation with no trend up or down from $\mathrm{CD}$ or $\mathrm{CH}$ traces, suggesting that the attractive interactions between the chains when $\mathrm{Ca}^{2+}$ is present in the subphase are sufficient to largely prevent even the unsaturated part of GCB from being oxidised. Indeed, it appears that surprisingly, almost no reaction at all is occurring here-at least not one that is removing significant material from the interface. The longest timescale attempted for this system was slightly short of $3 \mathrm{~h}$, and no removal of material from the interface was observed over this timescale, though the signal was significantly less stable than for the other systems, with around $30 \%$ variability between the extremes (coloured symbols in Figure 8), however no more than 10\% loss between the starting conditions and the signal after 10,000 s (extended neutron data from the experiment illustrated in Figure 8 are available in the repository, Woden et al., 2018) [49]. A similarly surprising protection of a surfactant from attack by a different oxidant at the air-water interface has very recently been reported by Zhang et al. [50] for $\mathrm{OH} \bullet$-initiated oxidation of monolayers of 1,2-dipalmitoyl-sn-glycero-3-phosphocholine (DPPC) and 1-palmitoyl-2-oleoyl-sn-glycero-3-phospho-(1'-rac-glycerol) (POPG): cholesterol that is present in the lipid layer appears to be able to increase the order of lipid packing and lower the permeability and hinder subsequent oxidation of the lipid layers by $\mathrm{OH} \bullet$ at the air-water interface.

\subsection{Two Component (GCB/POA) Monolayer Oxidation}

Introducing a double bond into GCB's co-component by using POA instead of PA should disrupt the formation of a regular, stable film structure. In addition, $\mathrm{POA}$ is itself reactive towards $\mathrm{NO}_{3} \bullet$, as it has a double bond (the reaction of a single component POA monolayer with $\mathrm{NO}_{3} \bullet$ has recently been reported by us [39]). A $d$-GCB/ $h$-POA contrast (1:1 mass ratio) was chosen, since deuterated POA is not readily commercially available and is not the main focus of the present study. Therefore, the neutron reflectometry data (and the $\mathrm{CD}$ trace from the IRRAS data) will follow the saturated part of GCB, and the unsaturated part of GCB, as well as the reactive POA, will be represented in the $\mathrm{CH}$ trace of the IRRAS data.

Figure 9 shows the neutron reflectometry data from this experiment (black circles and left ordinate) and, once again, the lack of any trend downward suggests that the saturated portion of GCB remains at the interface after oxidation. The fate of the unsaturated portion of GCB is difficult to disentangle from that of the POA component as both contribute to the same IRRAS band and are invisible in the NR data. The longest neutron reflectivity data collection for this system was just below $3 \mathrm{~h}$, with significant signal fluctuations (similar to those seen in Figure 8) of around $40 \%$ between the extremes, however no discernible downward trend (a maximum of $10 \%$ loss between starting conditions and the signal after 10,000 s); these extended neutron data are available in the repository (Woden et al., 2018) [49].

The IRRAS data in Figure 9 show that the $\mathrm{CH}$ peak areas decay to almost unmeasurable levels (only the $\mathrm{CH}$ symmetric stretch still registers at the end of the experiment), and this could mean that the unsaturated chain of GCB has been removed from the surface completely. This would contrast with the results from single component (GCB) monolayers, where some $\mathrm{CH}$ signal remains. However, there is less GCB overall in this system than in the single component GCB system, and the IRRAS signal is highly dependent upon surface orientation at low concentrations. It is thus possible that there was not a measurable amount of $\mathrm{CH}$ signal attributable to GCB unsaturated chains at the start of the reaction, and that the IRRAS data in Figure 9 simply show the reaction of POA. It is generally more difficult to detect IRRAS signals from disordered monolayers such as this [46] (indeed, as mentioned in the caption for Figure 9, only the asymmetric stretch was detectable for the CD bonds in this experiment and, in a repeat experiment, no CD bands were detectable at all). The fact that the CD trace drops when there is no change in the neutron reflectivity signal suggests that a re-orientation of GCB at the surface may occur after POA reacts, making GCB harder to detect by IRRAS. It is thus not possible to say from 
the IRRAS data alone whether or not the greater reduction in $\mathrm{CH}$ signal for this system indicates any difference in the reaction of the unsaturated chain of GCB. Custom synthesis of different deuteration contrasts could shed light on this: e.g., the study of two component $(d-\mathrm{POA} / d-\mathrm{GCB})$ monolayers would allow a more detailed exploration of this effect, however these compounds are currently not commercially available. Deuteration of the unsaturated tail of GCB would also allow for experiments to probe in greater detail the fate of that part of the molecule.

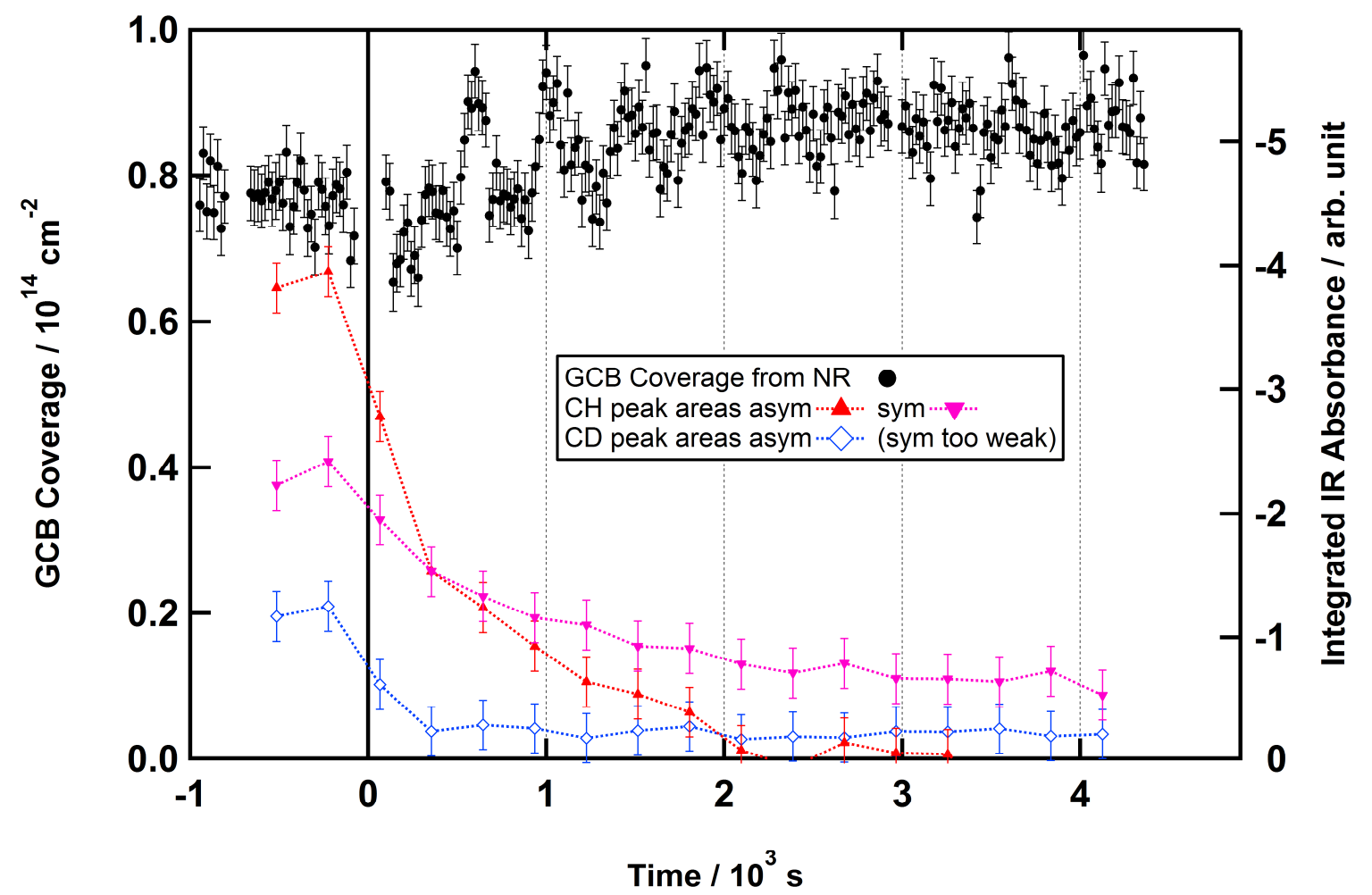

Figure 9. Oxidation of a two component (GCB/POA) monolayer on pure water-NR (black circles and left ordinate) and IRRAS (coloured symbols and right ordinate) data as a function of time. We spread a monolayer of $\sim 6.5 \times 10^{-5} \mathrm{~L}$ from a spreading solution containing $\sim 0.5 \mathrm{~g} \mathrm{~L}^{-1}$ of $d$-GCB and $\sim 0.5 \mathrm{~g} \mathrm{~L}^{-1}$ of $h$-POA in $\mathrm{CHCl}_{3} . \mathrm{NO}_{3} \bullet$ was admitted at $t=0 \mathrm{~s}$ at a concentration of $\sim 4.4 \times 10^{9} \mathrm{~cm}^{-3}$. The integrated absorbance areas for the IRRAS data were calculated for $2110-2070 \mathrm{~cm}^{-1}$ for CD bonds (one asymmetric stretch as blue diamonds; the symmetric stretch was too weak) and for $2868-2833 \mathrm{~cm}^{-1}$ and $2945-2898 \mathrm{~cm}^{-1}$ for $\mathrm{CH}$ bonds (one symmetric and one asymmetric stretch; coloured triangles).

In summary, the neutron reflectometry signal is consistently unmoved by the introduction of the oxidant $\mathrm{NO}_{3} \bullet$. While the signal is seen to change during the reaction of the mixed GCB/PA film on $\mathrm{CaCl}_{2}$ aqueous solution and of the mixed GCB/POA film on pure water, the reflectivity is not significantly altered between the pre-oxidation and post-oxidation states. This finding suggests the occurrence of re-organisation of the multi-component film surfaces during the reaction. The IRRAS data show different behaviour for the $\mathrm{CH}$ and $\mathrm{CD}$ stretches, demonstrating the usefulness of our approach of simultaneous observation by NR and IRRAS. The $\mathrm{CH}$ stretches show a reduction, though not to zero, for the reactions of pure GCB and for GCB/PA monolayers on pure water, while they show surprisingly no reduction during the reaction of mixed GCB/PA monolayers on $\mathrm{CaCl}_{2}$ aqueous solution. The $\mathrm{CH}$ stretches show a reduction to zero for $\mathrm{GCB} / \mathrm{POA}$ on pure water. The $\mathrm{CD}$ stretches are generally weaker and more difficult to reliably detect. However, they are sensitive to the same parts of the molecules as NR, so this is not a significant issue in our experimental system. They do not, within experimental error, show a decrease in signal across the reactions, except for the mixed 
GCB/POA monolayers where we have a mixture of two unsaturated surfactants that are both expected to undergo changes during $\mathrm{NO}_{3} \bullet$-initiated oxidation.

\section{Conclusions}

Our neutron reflectometry data clearly show that the key night-time atmospheric oxidant, $\mathrm{NO}_{3} \bullet$, is unable to remove (or significantly reduce the surface concentration of) a model lipopolysaccharide monolayer (both as a pure monolayer and as a model mixed monolayer with palmitic acid) from either a pure water or salt water subphase on the timescales investigated. These timescales were $5 \mathrm{~h}$ for the single component GCB monolayers on a pure water system, and $3 \mathrm{~h}$ for the other systems that were investigated. No measurable decrease was observed over these timescales within the margin for error of the measurement. These experimental uncertainties account for the maximum possible losses reported (we have not observed any measurable loss of material from the surface, however simply cannot rule out low loss rates within the margin for error of our experiments). Indeed, $\mathrm{NO}_{3} \bullet$ is known to have another route to reaction with organic species other than attacking a carbon-carbon double bond [23]: it can abstract hydrogen atoms via a homolytic process to create nitric acid, leaving a free radical on the carbon chain, which can then engage in back-biting reactions and attack $\mathrm{O}_{2}$ in order to produce a range of oxidised products. However, these alternative reactions are not significantly removing deuterated material from the air-water interface over the timescales that we have studied. We cannot rule out that these reactions are occurring as it is possible that early products from these processes are being produced yet remain at the interface. Nevertheless, in terms of atmospheric consequences, we can confidently state that $\mathrm{NO}_{3} \bullet$ oxidation does not remove our model marine aerosol monolayers at a rate that is sufficient to render the monolayers atmospherically irrelevant. This imperviousness to removal via oxidative attack on carbon-carbon double bonds is something that has also been observed in samples of aerosols bearing organic surface monolayers that have been collected in the field [35].

Our IRRAS data suggest that some reaction does occur, and that the unsaturated tail of the lipopolysaccharide monolayer is reacting with the oxidant. Surprisingly though, such an oxidative decay is not observed for the mixed monolayer on a $\mathrm{CaCl}_{2}$ subphase, probably due to the stabilisation of the system by enhanced chain-chain interactions. We are not aware of previous reports of unsaturated surfactants being protected from attack by atmospheric oxidants at the air-water interface via chain-chain interactions induced by ions in the subphase. This is a particularly interesting finding, since it is very likely that in atmospheric conditions a range of ions will be present in the aerosol droplets; therefore this process may provide an alternative explanation [22,51,52] for extended atmospheric residence times that have been found for reactive species and may have important health implications [53].

Both IRRAS and neutron data together are unequivocal that the saturated tail remains at the air-water interface despite exposure to $\mathrm{NO}_{3} \bullet$. We thus conclude that it is likely that aerosols produced from the sea-surface microlayer at night will remain covered in surfactant molecules on atmospherically relevant timescales; extended atmospheric lifetimes of these molecules may reduce the droplet's surface tension and may also affect the transport of species across the air-water interface.

Author Contributions: B. Woden (née Thomas): experimental setup, design, and assembly; off-line experiments; neutron beam time experiments; data processing and handling; manuscript writing; production of figures. M. Hagreen: neutron beam time experiments. M.W.A. Skoda: initial idea for study; experimental setup, design, and assembly; neutron beam time experiments; manuscript editing; neutron beamline operation. C. Pfrang: initial idea for study; experimental setup, design, and assembly; neutron beam time experiments; manuscript editing; project oversight.

Funding: This research was funded by NERC (National Environmental Research Council), STFC (Science and Technology Facilities Council) and ISIS Neutron and Muon Source (INTER experiment RB 1620451, doi:10.5286/ISIS.E.84424054). 
Acknowledgments: The experimental setup was built and assembled in concert with the workshop, soft matter, and sample environment teams at the ISIS Neutron and Muon Source; the Brewster angle microscope was made available by Diamond Light Source.

Conflicts of Interest: The authors declare no conflict of interest. The funders had no role in the design of the study; in the collection, analyses, or interpretation of the data; in the writing of the manuscript; or in the decision to publish the results.

\section{References}

1. Gill, P.S.; Graedel, T.E.; Weschler, C.J. Organic films on atmospheric aerosol particles, fog droplets, cloud droplets, raindrops, and snowflakes. Rev. Geophys. 1983, 21, 903. [CrossRef]

2. Ellison, G.B.; Tuck, A.F.; Vaida, V. Atmospheric processing of organic aerosols. J. Geophys. Res. 1999, 104, 11633-11641. [CrossRef]

3. Donaldson, D.J.; Vaida, V. The influence of organic films at the air-aqueous boundary on atmospheric processes. Chem. Rev. 2006, 106, 1445-1461. [CrossRef] [PubMed]

4. Stevens, B.; Feingold, G. Untangling aerosol effects on clouds and precipitation in a buffered system. Nature 2009, 461, 607-613. [CrossRef] [PubMed]

5. Ambaum, M.H.P. Thermal Physics of the Atmosphere, 1st ed.; Wiley-Blackwell: Reading, UK, 2010; ISBN 9780470745151.

6. Barnes, G.T. Permeation through monolayers. Colloids Surf. A Physicochem. Eng. Asp. 1997, 126, $149-158$. [CrossRef]

7. Gaines, G.L. Insoluble Monolayers at the Liquid Gas. Interface; Interscience Publishers: Geneva, Switzerland, 1966.

8. La Mer, V.K. Retardation of Evaporation by Monolayers: Transport. Processes; Academic Press Inc.: London, UK, 1962.

9. La Mer, V.K. The transport of water through monolayers of long-chain n-paraffinic alcohols. J. Colloid Sci. 1964, 19, 673-684. [CrossRef]

10. Benjamin, I. Chemical Reactions and Solvation at Liquid Interfaces: A Microscopic Perspective. Chem. Rev. 1996, 96, 1449-1476. [CrossRef] [PubMed]

11. Garrett, W.D. Retardation of Water Drop Evaporation with Monomolecular Surface Films. J. Atmos. Sci. 1971, 28, 816-819. [CrossRef]

12. Ray, A.K.; Devakottai, B.; Souyri, A.; Huckaby, J.L. Evaporation characteristics of droplets coated with immiscible layers of nonvolatile liquids. Langmuir 1991, 7, 525-531. [CrossRef]

13. Rideal, E.K. On the Influence of Thin Surface Films on the Evaporation of Water. J. Phys. Chem. 1924, 29, 1585-1588. [CrossRef]

14. Gilman, J.B.; Eliason, T.L.; Fast, A.; Vaida, V. Selectivity and stability of organic films at the air-aqueous interface. J. Colloid Interface Sci. 2004, 280, 234-243. [CrossRef] [PubMed]

15. Lo, J.-H.A.; Lee, W.-M.G. Effect of surfactant film on solubility of hydrophobic organic compounds in fog droplets. Chemosphere 1996, 33, 1391-1408. [CrossRef]

16. Mmereki, B.T.; Chaudhuri, S.R.; Donaldson, D.J. Enhanced Uptake of PAHs by Organic-Coated Aqueous Surfaces. J. Phys. Chem. A 2003, 107, 2264-2269. [CrossRef]

17. Mmereki, B.T.; Donaldson, D.J. Laser induced fluorescence of pyrene at an organic coated air-water interface. Phys. Chem. Chem. Phys. 2002, 4, 4186-4191. [CrossRef]

18. Tomoaia-Cotisel, M.; Cadenhead, D.A. The interaction of procaine with stearic acid monolayers at the air/water interface. Langmuir 1991, 7, 964-974. [CrossRef]

19. Forestieri, S.D.; Staudt, S.M.; Kuborn, T.M.; Faber, K.; Ruehl, C.R.; Bertram, T.H.; Cappa, C.D. Establishing the impact of model surfactants on cloud condensation nuclei activity of sea spray aerosol mimics. Atmos. Chem. Phys. 2018, 18, 10985-11005. [CrossRef]

20. Ruehl, C.R.; Davies, J.F.; Wilson, K.R. An interfacial mechanism for cloud droplet formation on organic aerosols. Science 2016, 351, 1447-1450. [CrossRef] [PubMed]

21. Ovadnevaite, J.; Zuend, A.; Laaksonen, A.; Sanchez, K.J.; Roberts, G.; Ceburnis, D.; Decesari, S.; Rinaldi, M.; Hodas, N.; Facchini, M.; et al. Surface tension prevails over solute effect in organic-influenced cloud droplet activation. Nature 2017, 546, 637-641. [CrossRef] [PubMed]

22. Pfrang, C.; Rastogi, K.; Cabrera, E.; Seddon, A.M.; Dicko, C.; Labrador, A.; Plivelic, T.; Cowieson, N.; Squires, A.M. Complex Three-Dimensional Self-Assembly in Proxies for Atmospheric Aerosols. Nat. Commun. 2017, 8, 1724. [CrossRef] [PubMed] 
23. Wayne, R.P.; Barnes, I.; Biggs, P.; Burrows, J.P.; Canosa-Mas, C.E.; Hjorth, J.; Le Bras, G.; Moortgat, G.K.; Perner, D.; Poulet, G.; et al. The nitrate radical: Physics, chemistry, and the atmosphere. Atmos. Environ. 1991, 25, 1-203. [CrossRef]

24. Khan, M.A.H.; Cooke, M.C.; Utembe, S.R.; Archibald, A.T.; Derwent, R.G.; Xiao, P.; Percival, C.J.; Jenkin, M.E.; Morris, W.C.; Shallcross, D.E. Global modeling of the nitrate radical $\left(\mathrm{NO}_{3}\right)$ for present and pre-industrial scenarios. Atmos. Res. 2015, 164-165, 347-357. [CrossRef]

25. Pfrang, C.; King, M.D.; Canosa-Mas, C.E.; Wayne, R.P. Correlations for gas-phase reactions of $\mathrm{NO}_{3}, \mathrm{OH}_{\text {and }}$ $\mathrm{O}_{3}$ with alkenes: An update. Atmos. Environ. 2006, 40, 1170-1179. [CrossRef]

26. Chapleski, R.C., Jr.; Zhang, Y.; Troya, D.; Morris, J.R. Heterogeneous chemistry and reaction dynamics of the atmospheric oxidants, $\mathrm{O}_{3}, \mathrm{NO}_{3}$, and $\mathrm{OH}$, on organic surfaces. Chem. Soc. Rev. 2016, 45, 3731-3746. [CrossRef] [PubMed]

27. Pfrang, C.; Martin, R.S.; Canosa-Mas, C.E.; Wayne, R.P. Gas-phase reactions of $\mathrm{NO}_{3}$ and $\mathrm{N}_{2} \mathrm{O}_{5}$ with (Z)-hex-4-en-1-ol, (Z)-hex-3-en-1-ol ('leaf alcohol'), (E)-hex-3-en-1-ol, (Z)-hex-2-en-1-ol and (E)-hex-2-en-1-ol. Phys. Chem. Chem. Phys. 2006, 8, 354-363. [CrossRef] [PubMed]

28. Pfrang, C.; Martin, R.S.; Nalty, A.; Waring, R.; Canosa-Mas, C.E.; Wayne, R.P. Gas-phase rate coefficients for the reactions of nitrate radicals with (Z)-pent-2-ene, (E)-pent-2-ene, (Z)-hex-2-ene, (E)-hex-2-ene, (Z)-hex-3-ene, (E)-hex-3-ene and (E)-3-methylpent-2-ene at room temperature. Phys. Chem. Chem. Phys. 2005, 7, 2506-2512. [CrossRef] [PubMed]

29. Pfrang, C.; Baeza Romero, M.T.; Cabanas, B.; Canosa-Mas, C.E.; Villanueva, F.; Wayne, R.P. Night-time tropospheric chemistry of the unsaturated alcohols (Z)-pent-2-en-1-ol and pent-1-en-3-ol: Kinetic studies of reactions of $\mathrm{NO}_{3}$ and $\mathrm{N}_{2} \mathrm{O}_{5}$ with stress-induced plant emissions. Atmos. Environ. 2007, 41, 1652-1662. [CrossRef]

30. King, M.D.; Rennie, A.R.; Thompson, K.C.; Fisher, F.N.; Dong, C.C.; Thomas, R.K.; Pfrang, C.; Hughes, A.V. Oxidation of oleic acid at the air-water interface and its potential effects on cloud critical supersaturations. Phys. Chem. Chem. Phys. 2009, 11, 7699-7707. [CrossRef] [PubMed]

31. Thompson, K.C.; Rennie, A.R.; King, M.D.; Hardman, S.J.O.; Lucas, C.O.M.; Pfrang, C.; Hughes, B.R.; Hughes, A.V. Reaction of a Phospholipid Monolayer with Gas-Phase Ozone at the Air-Water Interface: Measurement of Surface Excess and Surface Pressure in Real Time. Langmuir 2010, 26, 17295-17303. [CrossRef] [PubMed]

32. Pfrang, C.; Sebastiani, F.; Lucas, C.O.M.; King, M.D.; Hoare, I.D.; Chang, D.; Campbell, R.A. Ozonolysis of methyl oleate monolayers at the air-water interface: Oxidation kinetics, reaction products and atmospheric implications. Phys. Chem. Chem. Phys. 2014, 16, 13220-13228. [CrossRef] [PubMed]

33. Sebastiani, F.; Campbell, R.A.; Pfrang, C. Complementarity of neutron reflectometry and ellipsometry for the study of atmospheric reactions at the air-water interface. RSC Adv. 2015, 5, 107105-107111. [CrossRef]

34. Stewart, D.J.; Almabrok, S.H.; Lockhart, J.P.; Mohamed, O.M.; Nutt, D.R.; Pfrang, C.; Marston, G. The kinetics of the gas-phase reactions of selected monoterpenes and cyclo-alkenes with ozone and the $\mathrm{NO}_{3}$ radical. Atmos. Environ. 2013, 70, 227-235. [CrossRef]

35. Jones, S.H.; King, M.D.; Ward, A.D.; Rennie, A.R.; Jones, A.C.; Arnold, T. Are organic films from atmospheric aerosol and sea water inert to oxidation by ozone at the air-water interface? Atmos. Environ. 2017, 161, 274-287. [CrossRef]

36. Huang, Y.; Barraza, K.M.; Kenseth, C.M.; Zhao, R.; Wang, C.; Beauchamp, J.L.; Seinfeld, J.H. Probing the $\mathrm{OH}$ Oxidation of Pinonic Acid at the Air-Water Interface Using Field-Induced Droplet Ionization Mass Spectrometry (FIDI-MS). J. Phys. Chem. A 2018, 122, 6445-6456. [CrossRef] [PubMed]

37. Rossignol, S.; Tinel, L.; Bianco, A.; Passananti, M.; Brigante, M.; Donaldson, D.J.; George, C. Atmospheric photochemistry at a fatty acid-coated air-water interface. Science 2016, 353, 699-702. [CrossRef] [PubMed]

38. Gross, S.; Iannone, R.; Xiao, S.; Bertram, A.K. Reactive uptake studies of $\mathrm{NO}_{3}$ and $\mathrm{N}_{2} \mathrm{O}_{5}$ on alkenoic acid, alkanoate, and polyalcohol substrates to probe nighttime aerosol chemistry. Phys. Chem. Chem. Phys. 2009, 11, 7792-7803. [CrossRef] [PubMed]

39. Sebastiani, F.; Campbell, R.A.; Rastogi, K.; Pfrang, C. Nighttime oxidation of surfactants at the air-water interface: Effects of chain length, head group and saturation. Atmos. Chem. Phys. 2018, 18, 3249-3268. [CrossRef]

40. Tervahattu, H.; Juhanoja, J.; Kupiainen, K. Identification of an organic coating on marine aerosol particles by TOF-SIMS. J. Geophys. Res. 2002, 107, 4319. [CrossRef] 
41. Adams, E.; Allen, H. Palmitic Acid on Salt Subphases and in Mixed Monolayers of Cerebrosides: Application to Atmospheric Aerosol Chemistry. Atmosphere 2013, 4, 315-336. [CrossRef]

42. Laß, K.; Friedrichs, G. Revealing structural properties of the marine nanolayer from vibrational sum frequency generation spectra. J. Geophys. Res. 2011, 116, C08042. [CrossRef]

43. Facchini, M.C.; Rinaldi, M.; Decesari, S.; Carbone, C.; Finessi, E.; Mircea, M.; Fuzzi, S.; Ceburnis, D.; Flanagan, R.; Nilsson, E.D.; et al. Primary submicron marine aerosol dominated by insoluble organic colloids and aggregates. Geophys. Res. Lett. 2008, 35, L17814. [CrossRef]

44. Lu, J.R.; Thomas, R.K.; Penfold, J. Surfactant layers at the air/water interface: Structure and composition. Adv. Colloid Interface Sci. 2000, 84, 143-304. [CrossRef]

45. Campbell, R.A.; Saaka, Y.; Shao, Y.; Gerelli, Y.; Cubitt, R.; Nazaruk, E.; Matyszewska, D.; Lawrence, M.J. Structure of surfactant and phospholipid monolayers at the air/water interface modeled from neutron reflectivity data. J. Colloid Interface Sci. 2018, 531, 98-108. [CrossRef] [PubMed]

46. Skoda, M.W.A.; Thomas, B.; Hagreen, M.; Sebastiani, F.; Pfrang, C. Simultaneous neutron reflectometry and infrared reflection absorption spectroscopy (IRRAS) study of mixed monolayer reactions at the air-water interface. RSC Adv. 2017, 7, 34208-34214. [CrossRef]

47. Nelson, A. Co-refinement of multiple-contrast neutron/X-ray reflectivity data using MOTOFIT. J. Appl. Crystallogr. 2006, 39, 273-276. [CrossRef]

48. King, M.D.; Rennie, A.R.; Pfrang, C.; Hughes, A.V.; Thompson, K.C. Interaction of nitrogen dioxide $\left(\mathrm{NO}_{2}\right)$ with a monolayer of oleic acid at the air-water interface-A simple proxy for atmospheric aerosol. Atmos. Environ. 2010, 44, 1822-1825. [CrossRef]

49. Woden, B.; Skoda, M.W.A.; Hagreen, M.; Pfrang, C. Electronic Supplementary Information for the Manuscript "Night-Time Oxidation of a Monolayer Model for the Air-Water Interface of Marine Aerosols—A Study by Simultaneous Neutron Reflectometry and in Situ Infra-Red Reflection Absorption Spectroscopy (IRRAS)". 2018. Available online: http:/ / researchdata.reading.ac.uk/168/15/Readme.txt (accessed on 12 September 2018 ).

50. Zhang, X.; Barraza, K.M.; Beauchamp, J.L. Cholesterol provides nonsacrificial protection of membrane lipids from chemical damage at air-water interface. Proc. Natl. Acad. Sci. USA 2018, 115, 3255-3260. [CrossRef] [PubMed]

51. Pfrang, C.; Shiraiwa, M.; Pöschl, U. Chemical ageing and transformation of diffusivity in semi-solid multi-component organic aerosol particles. Atmos. Chem. Phys. 2011, 11, 7343-7354. [CrossRef]

52. Shiraiwa, M.; Ammann, M.; Koop, T.; Pöschl, U. Gas uptake and chemical aging of semisolid organic aerosol particles. Proc. Natl. Acad. Sci. USA 2011, 108, 11003-11008. [CrossRef] [PubMed]

53. Socorro, J.; Lakey, P.S.J.; Han, L.; Berkemeier, T.; Lammel, G.; Zetzsch, C.; Pöschl, U.; Shiraiwa, M. Heterogeneous $\mathrm{OH}$ Oxidation, Shielding Effects, and Implications for the Atmospheric Fate of Terbuthylazine and Other Pesticides. Environ. Sci. Technol. 2017, 51, 13749-13754. [CrossRef] [PubMed]

(C) 2018 by the authors. Licensee MDPI, Basel, Switzerland. This article is an open access article distributed under the terms and conditions of the Creative Commons Attribution (CC BY) license (http://creativecommons.org/licenses/by/4.0/). 